\title{
Perception of quality of health delivery and health insurance subscription in Ghana
}

\author{
Joshua Amo-Adjei ${ }^{1,2^{*}}$, Prince Justin Anku ${ }^{2}$, Hannah Fosuah Amo ${ }^{3}$ and Mavis Osei Effah ${ }^{4}$
}

\begin{abstract}
Background: National health insurance schemes (NHIS) in developing countries and perhaps in developed countries as well is a considered a pro-poor intervention by helping to bridge the financial burden of access to quality health care. Perceptions of quality of health service could have immense impacts on enrolment. This paper shows how perception of service quality under Ghana's insurance programme contributes to health insurance subscription.

Methods: The study used the 2014 Ghana Demographic and Health Survey (GDHS) dataset. Both descriptive proportions and binary logistic regression techniques were applied to generate results that informed the discussion.

Results: Our results show that a high proportion of females (33\%) and males (35\%) felt that the quality of health provided to holders of the NHIS card was worse. As a result, approximately $30 \%$ of females and 22\%who perceived health care as worse by holding an insurance card did not own an insurance policy. While perceptions of differences in quality among females were significantly different (AOR $=0.453[95 \% \mathrm{Cl}=0.375,0.555]$, among males, the differences in perceptions of quality of health services under the NHIS were independent in the multivariable analysis. Beyond perceptions of quality, being resident in the Upper West region was an important predictor of health insurance ownership for both males and females.

Conclusion: For such a social and pro-poor intervention, investing in quality of services to subscribers, especially women who experience enormous health risks in the reproductive period can offer important gains to sustaining the scheme as well as offering affordable health services.
\end{abstract}

Keywords: Quality, Health care, Health insurance, Subscription, Ghana

\section{Background}

Healthcare financing remain a major concern for many countries globally, especially middle and low-income countries [1]. In the light of rising burden of noncommunicable diseases (NCDs) coupled with the already high prevalence of infectious diseases, the challenges to healthcare financing has become more pressing. In many middle and low-income settings, financing healthcare is worsened by the wide socioeconomic inequalities $[2,3]$. Health insurance, which involves pooling risk and resources, is widely regarded as a mean to ensure equity in health care, protect households from catastrophic health spending and improve access to healthcare especially among the poor and vulnerable in society [4-6].

\footnotetext{
* Correspondence: Joshua.amo-adjei@ucc.edu.gh

${ }^{1}$ African Population and Health Research Centre, Nairobi, Kenya

${ }^{2}$ Department of Population and Health, University of Cape Coast, Cape Coast, Ghana

Full list of author information is available at the end of the article
}

Health insurance in developing countries offers a great deal of opportunity for people, especially the poor to access healthcare anytime the need arises. However, in a number of countries where health insurance is largely regarded as a pro-poor intervention, enrolment is much lower than projections. Factors such as poverty, perceived poor quality of healthcare to clients on insurance, poor perception about the concept of health insurance, lack of information, high number of people in the informal sector, low levels of education, inefficient institutional coordination, lack of trust, among others have been documented as responsible for the low enrolment onto health insurance in many low-middle income countries [7-12].

Although Ghana's national health insurance programme is considered one of the best performers in sub-Saharan Africa, a lot more need to be done to propel enrolment in order to reap the anticipated benefits for establishing the programme [13]. For instance, in 2011, while $31 \%$ of 
females had never enrolled in the scheme, it was $44 \%$ among males. Three key reasons for non-subscriptions among both sexes were; high premium (females: $39 \%$; males: $32 \%$ ), "no need for health insurance" (females: $21 \%$; $28 \%$ for males) and "lack of trust in the NHIS" (females: 6 \%; males: 5 \%) [14]. The situation in 2011 had barely changed by 2014 - around 6 in 10 women and half of men were covered by health insurance [15]. Thus, sub-optimal enrolment is a major challenge towards achieving a nationwide coverage of the scheme.

In this paper, we discuss how perceptions of quality of healthcare delivery under the scheme impacts on subscription rates in Ghana, which is a detour from existing studies, that have looked at either perceptions of quality of health delivery under the scheme [16] or perceptions of benefits under Ghana's health insurance [17]. While these studies advance our understanding of perceptions about the scheme, they failed to account for how these perceptions affect actual subscriptions. This study therefore becomes important in the light of frequent public criticisms about the performance of the scheme. For a scheme which relies extensively on membership subscriptions, negative perceptions about the quality of healthcare delivered to subscribers may negatively affect renewals and enrolments and ultimately, the survival of the scheme. To that extent, this study becomes useful for programmatic improvement and extending our understanding of the nuances involved in health insurance subscription in Ghana.

\section{Context of the study}

At independence, the healthcare delivery system was modelled around the practice in Britain. Under this system, healthcare services provided in public institutions were virtually free to all citizens. Overtime, this practice changed due to decline in economic fortunes, which made free healthcare unsustainable. Fees for healthcare services were introduced in 1985 and subsequently, in 1992, the "cash-and-carry" system was introduced where patients had to make full payment for all services rendered at the various health facilities [18]. The "cash-andcarry" system soon became unpopular as it resulted in low utilization of healthcare services especially among the poor of the population. The deteriorating health situation in the country prompted government to look for alternative means of providing quality and affordable healthcare to all Ghanaians especially the poor and the vulnerable, leading the extension of the National Health Insurance Scheme (NHIS) nationwide in 2003 [19]. Prior to that there were some district level mutual health insurance schemes of which the Nkoranza model is popularly mentioned see, [20]. In essence, the policy was a pro-poor strategy of extending healthcare access to population hitherto would not be able to access health services easily arising from financing difficulties. The range of premiums charged currently ranges between GHC7.2 and $\mathrm{GHC} 48 \approx \$ 1.9-\$ 12.3$, depending on whether one resided in a relatively developed urban area or not. Other means of subscribing are $2.5 \%$ monthly Social Security and National Insurance Trust (SSNIT) remittance to the scheme on behalf of formal workers, explicit exemption from paying premiums by those categorized as vulnerable groups; the very poor, children below age 18, pregnant women, and people aged 70 years and above [21].

The scheme is run on the basis of a pre-defined package to subscribers and active members. Health conditions captured under the scheme cover about $95 \%$ of the endemic diseases in the country. Despite the huge potential benefits that are associated with the NHIS, enrolment onto the scheme continues to be far from optimum with lower enrolment among the poor even though the scheme is designed as pro-poor $[17,22,23]$. On the account of this, studies aiming at understanding some specific "threats" to increased subscriptions are worth pursuing.

\section{Methods}

This paper employed the 2014 Ghana Demographic and Health Survey (GDHS14) dataset to analyse our study variables. The GDHS14 was the sixth round of the surveys, which started in 1987/88 in a number of developing countries in Asia and Africa. The Ghana Statistical Service (GSS), the lead organisation responsible for this survey collaborated with the ICF Macro and the Ghana Health Service (GHS). The survey relied on multi-staged sampling, which involved the selection of 427 clusters/ enumeration areas (EAs) drawn from the 2010 Population and Housing Census. Of the total EAs, 216 were drawn from urban areas across the 10 administrative regions of the country using random techniques. The same approach was used to draw 211 clusters/EAs from rural areas bearing regional proportions in mind. In these clusters, a total of 12,831 households were selected with equal number of households per cluster. As a result, the sample was not self-weighting at the national level but weighting factors were computed for each cluster/EA to help generate results that reflect the regional share of the national population. Inclusion criteria were being a male or female between ages 15-49 and 15-59 respectively; de factor resident in the selected and informed consent duly granted. At a response rate of $97 \%, 9,656$ females and 4,609 males (response rate $95 \%$ ) participated in the survey. The dataset is freely available for public use on www.measuredhs.com. The questionnaires used for the 2014 GDHS is also appended to the final report published by Ghana Statistical Service (GSS), Ghana Health Service (GHS) (15).

Each respondent provided informed verbal and written consent to participate in the study. For respondent 
below 18 years (the statutory age for defining adulthood), parental or legal guardian consent followed by respondent assent was secured. Ethical approval for the data collection was provided by the Ethical Review Committee of Ghana Health Service, Accra, Ghana and the Institutional Review Board of ICF International, USA.

\section{Study variables}

The two key variables in this study are perception of service quality by holding an NHIS card (independent) coded as better $=1$, same $=2$, worse $=3$ and "don't know" $=8$ and ownership of an NHIS card (dependent variable) captured as "no" $=0$ and "yes" $=1$. However, for the sake of specificity, "don't know" in the case of the first variable was recoded to missing. To help us clearly decipher how robust our key explanatory variable relates to ownership of health insurance package, some theoretically relevant variables are included in the analysis. These are education (no education $=0$, primary $=1$, secondary $=3$ and higher $=4$ ), ethnicity $($ Akan $=1, \mathrm{Ga}$ / Dangme $=2$, Ewe $=3$, Mole-Dagbani $=4$, Gurma $=5$ and Others $=6$ ), wealth (poorest $=1$, poorer $=2$, middle/ average $=3$ richer $=4$, richest $=5$ ), religion (Orthodox Christian $=1 \quad$ [Catholic, Presbyterian, Methodist and Anglican], Pentecostal $/$ Charismatic $=2$, Other Christian $=3$, Islam $=4$ and $T$ raditional $/$ Spiritualist $=5$ ). Other variables were region of residence (Western $=1$, Central $=2$, Greater Accra $=3$, Volta $=4$, Eastern $=5$, Ashanti $=6$, BrongAhafo $=7$, Northern $=8$, Upper East $=9$ and Upper West $=10$ ), type of place of residence ( urban $=1$, rural $=$ $2)$, age $(15-19=1,20-24=2,25-29=3,30-34=4,35-39=$ $5,40-44=6,45-49=7,50-54=8$, and $55-59=9$ ) and occupation (not working $=0$, professional $/$ managerial/ clerical $=1$, sales $/$ services $=2$, agricultural employee/ employed $=3$ and skilled/unskilled manual $=4$ ).

\section{Analytical procedure}

The analysis proceeded on the assumption that if perception of service quality by holding an NHIS care was better, not different or worse, the effects will be observed on whether an individual had own health insurance or not. To verify this, we first explored the bivariate association between socioeconomic characteristics and perceptions of service quality by holding insurance card using descriptive statistics with corresponding Chi-square test of association. This followed by running a bivariate logistic regression between perception of quality and ownership of health insurance. The next level was to control for the effects of other possible factors on insurance subscription. Separate analyses were done for females and males, as the GDHS data files do not easily allow merging female and male datasets. The results are presented in odds ratios with values less than 1 indicating less likelihood of a respondent being subscriber while those above 1 indicate higher likelihood.

\section{Results}

Of the 7,304 females who responded to the question on quality of service by holding NHIS card, about $33 \%$ each perceived service to be better, same and worse. Just about the same pattern noted among females was observed among males; approximately $34 \%$ thought that service under the scheme was better and worse respectively while $31 \%$ of them perceived no differences in service quality between NHIS subscribers and non-card subscribers. Among males, a sligth majority (51 \%) compared to an absolute majority of females $(62.4 \%)$ who were covered by the NHIS. Regarding other characteristics of sampled population, a higher proportion of females were in the richest wealth quintile $(23 \%)$, had attained secondary education (56.8\%), resident in the Greater Accra region (20.2\%), currently living with a man or married (56.6\%), living in an urban area (53.8\%) and were employed in the sales/services sector (38.8\%). The characteristics of males also followed similar trajectory except that in terms of occupation, agricultural workers constituted the highest proportion (31.8\%).

\section{Service quality by holding NHIS and socioeconomic variables}

Tables 1 and 2 show bivariate association between socioeconomic variables and perceptions about quality of service quality by holding an NHIS card, disaggregated by sex. In terms of education and perception of quality, we observed that with rising education, females were more likely to rate service under the NHIS as worse. Perceptions about service quality by holding NHIS shifted towards worse with rising household affluence. Females resident in the Western region were more likely to perceive service quality by holding NHIS as better. However, females in the Ashanti region were more inclined to indicate that the service quality under NHIS as worse. While females resident in urban areas rated service quality to be worse, those in rural areas indicated it was better. Significant differences in perceptions about service quality among females also existed by age, religion, ethnicity, marital status and occupation (Table 1).

Table 2 presents perceptions about service quality among males. While a higher proportion of males with no education $(47 \%)$ said service quality was better by holding NHIS, about $38 \%$ of those with higher education thought service was worse with NHIS. The poorest among males were more likely to state that service quality by holding NHIS was better while richest males tended to rate NHIS services poor. Males in the Central region tended to rate service under the NHIS as better while their counterparts in the Greater Accra region 
Table 1 Perception of service quality by holding NHIS by socioeconomic status among Ghanaian females

\begin{tabular}{|c|c|c|c|c|}
\hline \multirow[t]{2}{*}{ Explanatory variables } & \multicolumn{4}{|c|}{ Perception of service quality by holding NHIS } \\
\hline & Better (\%) & Same (\%) & Worse (\%) & $\mathrm{N}$ \\
\hline \multicolumn{5}{|c|}{ Highest educational level $\left(x^{2}=128.66 ; p<0.000\right)$} \\
\hline No education & 39.5 & 36.7 & 23.8 & 1,332 \\
\hline Primary & 35.3 & 35.4 & 29.3 & 1,219 \\
\hline Secondary & 33.1 & 31.1 & 35.8 & 4,265 \\
\hline Higher & 19.5 & 35.7 & 44.8 & 487 \\
\hline \multicolumn{5}{|l|}{ Wealth index $\left(x^{2}=259.17 ; p<0.000\right)$} \\
\hline Poorest & 45.5 & 33.8 & 20.7 & 1,155 \\
\hline Poorer & 42.2 & 33.3 & 24.5 & 1,214 \\
\hline Middle & 35.5 & 31.9 & 32.6 & 1,496 \\
\hline Richer & 29.4 & 33.1 & 37.5 & 1,670 \\
\hline Richest & 22.9 & 33.7 & 43.4 & 1,767 \\
\hline \multicolumn{5}{|l|}{ Region $\left(x^{2}=722.82 ; p<0.000\right)$} \\
\hline Western & 56.0 & 31.7 & 12.3 & 841 \\
\hline Central & 38.4 & 40.7 & 20.9 & 636 \\
\hline Greater Accra & 18.4 & 42.6 & 39.1 & 1,237 \\
\hline Volta & 28.6 & 31.4 & 40.0 & 598 \\
\hline Eastern & 48.6 & 25.0 & 26.4 & 713 \\
\hline Ashanti & 18.8 & 27.3 & 53.9 & 1,478 \\
\hline Brong-Ahafo & 34.1 & 27.2 & 38.7 & 683 \\
\hline Northern & 44.4 & 37.4 & 18.2 & 602 \\
\hline Upper East & 41.7 & 41.9 & 16.3 & 326 \\
\hline Upper West & 47.7 & 27.7 & 24.5 & 185 \\
\hline \multicolumn{5}{|c|}{ Type of place of residence $\left(x^{2}=154.54 ; p<0.000\right)$} \\
\hline Urban & 26.6 & 34.0 & 39.5 & 3,940 \\
\hline Rural & 42.2 & 32.2 & 25.7 & 3,363 \\
\hline \multicolumn{5}{|c|}{ Current marital status $\left(X^{2}=12.45 ; p<0.014\right)$} \\
\hline Never in union & 34.8 & 31.9 & 33.4 & 2,279 \\
\hline Currently in union/living with a mans & 33.6 & 33.8 & 32.5 & 4,314 \\
\hline Formerly in union/living with a man & 30.9 & 33.3 & 35.8 & 710 \\
\hline \multicolumn{5}{|l|}{ Age $\left(x^{2}=36.35 ; p<0.000\right)$} \\
\hline $15-19$ & 38.3 & 34.9 & 26.8 & 1,189 \\
\hline $20-24$ & 34.2 & 30.9 & 34.8 & 1,232 \\
\hline $25-29$ & 32.3 & 33.6 & 34.2 & 1,298 \\
\hline $30-34$ & 29.9 & 34.8 & 35.3 & 1,081 \\
\hline $35-39$ & 34.3 & 33.0 & 32.7 & 1,064 \\
\hline $40-44$ & 31.7 & 32.4 & 36.0 & 799 \\
\hline $45-49$ & 35.4 & 31.8 & 32.7 & 638 \\
\hline \multicolumn{5}{|l|}{ Religion $\left(x^{2}=80.88 ; p<0.000\right)$} \\
\hline Orthodox & 34.6 & 32.4 & 33.0 & 1,866 \\
\hline Pentecostal & 30.3 & 33.5 & 36.3 & 2,920 \\
\hline Other Christian & 36.4 & 28.6 & 34.9 & 1,054 \\
\hline Islam & 37.6 & 35.4 & 27.0 & 1,181 \\
\hline Traditional/others & 38.0 & 42.3 & 19.7 & 281 \\
\hline
\end{tabular}


Table 1 Perception of service quality by holding NHIS by socioeconomic status among Ghanaian females (Continued)

\begin{tabular}{|c|c|c|c|c|}
\hline \multicolumn{5}{|c|}{ Ethnicity $\left(x^{2}=183.00 ; p<0.000\right)$} \\
\hline Akan & 33.8 & 31.0 & 35.2 & 3,665 \\
\hline Ga/Dangme & 32.2 & 34.8 & 33.0 & 495 \\
\hline Ewe & 28.0 & 33.3 & 38.7 & 938 \\
\hline Mole-Dagbani & 41.6 & 32.1 & 26.2 & 1,160 \\
\hline Gurma & 30.1 & 50.0 & 19.9 & 378 \\
\hline Others & 31.0 & 35.7 & 33.2 & 620 \\
\hline \multicolumn{5}{|c|}{ Occupation $\left(x^{2}=117.76 ; p<0.000\right)$} \\
\hline Not working & 38.8 & 34.6 & 26.7 & 1,705 \\
\hline Professional/Managerial & 23.9 & 30.9 & 45.3 & 533 \\
\hline Sales/Services & 29.7 & 32.7 & 37.6 & 2,830 \\
\hline Agricultural worker & 41.6 & 33.0 & 25.5 & 1,325 \\
\hline Skilled/Unskilled & 31.5 & 33.4 & 35.1 & 896 \\
\hline
\end{tabular}

Computed from 2014 GDHS

classified service quality under the NHIS as worse. About two-thirds of males in professional/clerical/ managerial employments indicated described NHIS services as worse.

\section{Multivariable analysis}

In this section, we report on the impacts of perceptions of service quality by holding NHIS and insurance ownership. For females (Table 3) who rated NHIS service poorly were significantly less likely to have an insurance cover $(\mathrm{OR}=0.453 ; 95 \% \mathrm{CI}=0.375,0.554)$. Similarly, males with similar views about the scheme were significantly less likely to have an insurance cover $(\mathrm{OR}=0.697$; $95 \% \mathrm{CI}=0.515,0.944)$ than those who rated the quality of health service as better using the NHIS payment option. After controlling other covariates of insurance ownership, the effects of negative perceptions on service quality under the NHIS remained significantly robust for females $(\mathrm{OR}=0.456 ; 95 \% \mathrm{CI}=0.373,0.549)$ but not so for males (Table 3).

On other covariates, whereas females with higher education $(\mathrm{OR}=2.196 ; 95 \% \mathrm{CI}=1.450,3.327)$ were significantly more likely to own health insurance, males in the same category were not significantly different than their counterparts with other levels of education. With respect to wealth, males in the highest quintile $(\mathrm{OR}=3.047$; $95 \% \mathrm{CI}=1.661,5.590)$ significantly tended to own health insurance than females $(\mathrm{OR}=1.709 ; 95 \% \mathrm{CI}=1.183$, 2.470 ) in similar category. The most outstanding result is the high odds of NHIS ownership in the Upper West region for both females $(\mathrm{OR}=9.494,95 \% \mathrm{CI}=3.753$, 24.02) and males $(\mathrm{OR}=11.11 ; 95 \% \mathrm{CI}=4.275,28.87)$. Another finding worth highlighting is the less likelihood of males in sales/services $(\mathrm{OR}=0.477 ; 95 \% \mathrm{CI}=0.291,0.783)$, agricultural sector $(\mathrm{OR}=0.429 ; 95 \% \mathrm{CI}=0.272,0.676)$ and skilled/unskilled manual labour $(\mathrm{OR}=0.452 ; 95 \% \mathrm{CI}=$ $0.289,0.706)$.

\section{Discussion}

This paper examined how health insurance subscription in Ghana is influenced/shaped by perceptions of health service quality when healthcare cost is paid for using NHIS card. This was necessary in the light of the overriding goal of a national health insurance programme in Ghana-creating wealth through health by making access equitable in the country. The results show that perception of service quality was strongly related to ownership of health insurance and this was more pronounced in females than males.

Overall, the results show similarity to previous research on reasons for non-enrolment in health insurance schemes, particularly in sub-Sahara Africa. Quality of services provided to subscribers compared to those making outof-pocket payments remains significant. For instance, the key reason for non-subscription and declining membership in a mutual health organisation (MHO) in Guinea Conakry was the poor quality of care offered to members of the scheme at health facilities [24]. Related findings have been reported about a community health insurance (CHI) in Uganda [25].

In terms of total enrolment in the insurance programme, our results evidence higher prevalence of subscription among women than men. Reasons that may account for this include: first, women are somewhat risk averse than men. Among men, low perception of risk could be attributed to male 'misconception' of physical superiority and therefore are unlikely to participate in programmes, which seek to pool and share risks associated with cost of health services. Literature on adoption of innovation also point out that men generally are late 
Table 2 Perception of service quality by holding NHIS by socioeconomic status among Ghanaian males

\begin{tabular}{|c|c|c|c|c|}
\hline \multirow[t]{2}{*}{ Explanatory variables } & \multicolumn{4}{|c|}{ Perception of service quality by holding NHIS } \\
\hline & Better (\%) & Same (\%) & Worse (\%) & $\mathrm{N}$ \\
\hline \multicolumn{5}{|c|}{ Highest educational level $\left(x^{2}=67.97 ; p<0.000\right)$} \\
\hline No education & 47.3 & 21.0 & 31.7 & 266 \\
\hline Primary & 43.1 & 37.5 & 19.5 & 282 \\
\hline Secondary & 32.0 & 31.3 & 36.7 & 1,692 \\
\hline Higher & 29.3 & 32.3 & 38.4 & 383 \\
\hline \multicolumn{5}{|l|}{ Wealth index $\left(x^{2}=97.97 ; p<0.000\right)$} \\
\hline Poorest & 48.1 & 25.7 & 26.2 & 460 \\
\hline Poorer & 41.4 & 30.7 & 27.9 & 442 \\
\hline Middle & 34.9 & 29.9 & 35.2 & 478 \\
\hline Richer & 26.0 & 34.7 & 39.3 & 573 \\
\hline Richest & 27.0 & 32.7 & 40.3 & 670 \\
\hline \multicolumn{5}{|l|}{ Region $\left(x^{2}=420.75 ; p<0.000\right)$} \\
\hline Western & 19.6 & 30.5 & 49.9 & 292 \\
\hline Central & 67.0 & 15.4 & 17.6 & 193 \\
\hline Greater Accra & 17.5 & 25.8 & 56.7 & 401 \\
\hline Volta & 35.6 & 32.2 & 32.2 & 209 \\
\hline Eastern & 33.3 & 37.6 & 29.1 & 269 \\
\hline Ashanti & 34.3 & 41.4 & 24.3 & 544 \\
\hline Brong-Ahafo & 16.2 & 43.0 & 40.8 & 271 \\
\hline Northern & 53.0 & 13.7 & 33.3 & 244 \\
\hline Upper East & 63.8 & 28.4 & 7.8 & 123 \\
\hline Upper West & 54.5 & 18.8 & 26.6 & 75 \\
\hline \multicolumn{5}{|c|}{ Type of place of residence $\left(x^{2}=29.80 ; p<0.000\right)$} \\
\hline Urban & 28.2 & 34.9 & 36.9 & 1,354 \\
\hline Rural & 40.9 & 27.0 & 32.1 & 1,271 \\
\hline \multicolumn{5}{|c|}{ Current marital status $\left(x^{2}=10.75 ; p<0.029\right)$} \\
\hline Never in union & 35.1 & 33.3 & 31.6 & 1,118 \\
\hline Currently in union/living with a mans & 34.4 & 29.0 & 36.6 & 1,387 \\
\hline Formerly in union/living with a man & 27.2 & 34.0 & 38.7 & 120 \\
\hline \multicolumn{5}{|l|}{ Age $\left(x^{2}=38.01 ; p<0.002\right)$} \\
\hline $15-19$ & 37.4 & 36.3 & 26.3 & 562 \\
\hline $20-24$ & 35.0 & 28.3 & 36.7 & 331 \\
\hline $25-29$ & 39.5 & 28.6 & 31.9 & 301 \\
\hline $30-34$ & 27.9 & 29.9 & 42.2 & 298 \\
\hline $35-39$ & 30.9 & 27.6 & 41.4 & 309 \\
\hline $40-44$ & 33.7 & 26.2 & 40.1 & 277 \\
\hline $45-49$ & 32.0 & 30.6 & 37.4 & 220 \\
\hline $50-54$ & 37.4 & 34.1 & 28.5 & 184 \\
\hline $55-59$ & 31.3 & 38.0 & 30.7 & 150 \\
\hline \multicolumn{5}{|l|}{ Religion $\left(x^{2}=32.52 ; p<0.000\right)$} \\
\hline Orthodox & 31.9 & 32.3 & 35.9 & 716 \\
\hline Pentecostal & 34.5 & 31.2 & 34.3 & 742 \\
\hline Other Christian & 26.5 & 34.3 & 39.1 & 458 \\
\hline
\end{tabular}


Table 2 Perception of service quality by holding NHIS by socioeconomic status among Ghanaian males (Continued)

\begin{tabular}{|c|c|c|c|c|}
\hline Islam & 41.0 & 27.3 & 31.7 & 507 \\
\hline Traditional/Others & 43.7 & 28.5 & 27.8 & 200 \\
\hline \multicolumn{5}{|c|}{ Ethnicity $\left(x^{2}=132.48 ; p<0.000\right)$} \\
\hline Akan & 30.6 & 32.5 & 36.9 & 1,287 \\
\hline Ga/Dangme & 26.0 & 33.0 & 41.0 & 179 \\
\hline Ewe & 31.1 & 29.5 & 39.5 & 339 \\
\hline Mole-Dagbani & 43.8 & 27.9 & 28.3 & 444 \\
\hline Gurma & 55.0 & 23.5 & 21.5 & 158 \\
\hline Others & 34.1 & 35.9 & 30.0 & 216 \\
\hline \multicolumn{5}{|c|}{ Occupation $\left(x^{2}=67.97 ; p<0.000\right)$} \\
\hline Not working & 35.1 & 37.0 & 27.9 & 408 \\
\hline Professional/Managerial & 32.5 & 27.3 & 40.2 & 435 \\
\hline Sales/Services & 29.7 & 32.7 & 37.6 & 278 \\
\hline Agricultural worker & 41.4 & 27.3 & 31.3 & 819 \\
\hline Skilled/Unskilled & 29.1 & 33.4 & 37.4 & 671 \\
\hline
\end{tabular}

Computed from 2014 GDHS

adopters (e.g. [26]) and are unlikely to own an insurance cover.

Also, the high enrolment of women more than men may be an artefact of prevailing policy of free health care for pregnant women. Under Ghana's health insurance policy, pregnant women are part of the exempt category. This is more plausible given the age inclusion criteria for males (15-59 years) and females (15-49y years). The majority of these women were either pregnant or had been in the last five years to survey. This position is further strengthened other results from the study - pregnant women at the time of the survey reported higher tendency of being a subscriber than those unsure or did not know they were pregnant; this is consistent with a similar study in Burkina Faso [27].

Regarding perception of service quality and NHIS subscription, our findings reveal the importance of improving quality of healthcare in general and particularly among subscribers given the pro-poor nature of the programme. Perhaps, the concurrent running of the scheme with outof-pocket payment could be contributing to perception of poor quality to subscribers. Martin and McMillan [28] noted that running a health insurance programme contemporarily with out-of-pocket payments might result in strict implementation of prescription, which can expose subscribers of health insurance to clinical consequences and thereby affect views of quality. It is imperative that quality of care in terms of convenience, scheme administrative arrangements, and provider attitudes can enhance enrolment if clients are satisfied with services provided by insurance providers [29].

Psychological theory also offers plausible reasons for female-male differential judgement of quality and how this affects outcomes. For instance, Darley and Smith [30] note that while females process information more comprehensively, consider both subjective and objective attributes of services and observant of delicate cues, men, on the other hand, are selective in information processing, use heuristics more frequently and are likely to miss details. This may account for the gender differences. Atinga, Abiiro [31] for instance observed that women were more likely to drop out of the NHIS due to quality concerns than males in informal settlements in Accra, Ghana. In a context where women in the reproductive ages (sample for this study) seem to have more life threatening health needs challenges as a result of childbirth see, [32], the health insurance managers ought to be concerned about total quality management. In a previous study, [33] the authors found that women enrolled in the NHIS were more likely to utilize antenatal services than those not enrolled regardless of socioeconomic status.

One striking finding is the high prevalence of NHIS ownership in the Upper West region among both males and females, albeit it is the poorest region in Ghana [34]. This is a positive observation in the sense that the NHIS is a pro-poor intervention. The equity goal in respect of access to health care is enhance with more registration in high poverty incidence areas. Unfortunately, however, in another high poverty incidence region, the Upper East, females were unlikely to own a health insurance, although more vulnerable to health problems during the reproductive period. Another finding worth our comment is the lower proportion of women in Ashanti region being subscribers to the NHIS. Perhaps, the trial of capitation provider-payment system started in the region, which received a lot of public criticisms, might be responsible for 
Table 3 Logistic regression results on perceptions of healthcare quality under NHIS and ownership of health insurance

\begin{tabular}{|c|c|c|c|c|c|c|c|c|}
\hline \multirow[b]{2}{*}{ Explanatory factors } & \multicolumn{4}{|l|}{ Females } & \multicolumn{4}{|l|}{ Males } \\
\hline & Model I & $95 \% \mathrm{Cl}$ & Model II & $95 \% \mathrm{Cl}$ & Model III & $95 \% \mathrm{Cl}$ & Model IV & $95 \% \mathrm{Cl}$ \\
\hline \multicolumn{9}{|c|}{ Perception of NHIS quality } \\
\hline Better & 1 & {$[1,1]$} & 1 & {$[1,1]$} & 1 & {$[1,1]$} & 1 & {$[1,1]$} \\
\hline Same & $0.708^{* *}$ & {$[0.574,0.874]$} & $0.699^{* *}$ & {$[0.561,0.871]$} & 0.868 & {$[0.644,1.168]$} & 0.973 & {$[0.724,1.308]$} \\
\hline Worse & $0.453^{* * *}$ & {$[0.373,0.549]$} & $0.456^{* * *}$ & {$[0.375,0.554]$} & $0.697^{*}$ & {$[0.515,0.944]$} & 0.781 & {$[0.575,1.062]$} \\
\hline \multicolumn{9}{|l|}{ Level of education } \\
\hline None & & & 1 & {$[1,1]$} & & & 1 & {$[1,1]$} \\
\hline Primary & & & 1.117 & {$[0.902,1.384]$} & & & 0.715 & {$[0.476,1.073]$} \\
\hline Secondary & & & $1.325^{* *}$ & {$[1.087,1.615]$} & & & 0.946 & {$[0.664,1.347]$} \\
\hline Higher/Tertiary & & & $2.196^{* * *}$ & {$[1.450,3.327]$} & & & 1.456 & {$[0.795,2.668]$} \\
\hline \multicolumn{9}{|l|}{ Wealth quintile } \\
\hline Poorest & & & 1 & {$[1,1]$} & & & 1 & {$[1,1]$} \\
\hline Poorer & & & 1.097 & {$[0.831,1.446]$} & & & $1.506^{*}$ & {$[1.002,2.262]$} \\
\hline Middle & & & 1.181 & {$[0.884,1.578]$} & & & 1.465 & {$[0.933,2.298]$} \\
\hline Richer & & & 1.201 & {$[0.865,1.668]$} & & & $2.159^{* *}$ & {$[1.289,3.614]$} \\
\hline Richest & & & $1.709^{* *}$ & {$[1.183,2.470]$} & & & $3.047^{* * *}$ & {$[1.661,5.590]$} \\
\hline \multicolumn{9}{|l|}{ Region } \\
\hline Western & & & 1 & {$[1,1]$} & & & 1 & {$[1,1]$} \\
\hline Central & & & 0.763 & {$[0.521,1.116]$} & & & 1.871 & {$[0.968,3.617]$} \\
\hline Greater Accra & & & 1.272 & {$[0.800,2.023]$} & & & 2.051 & {$[1.000,4.208]$} \\
\hline Volta & & & 1.268 & {$[0.804,1.998]$} & & & $3.314^{* *}$ & {$[1.601,6.863]$} \\
\hline Eastern & & & 1.260 & {$[0.824,1.927]$} & & & 1.317 & {$[0.713,2.435]$} \\
\hline Ashanti & & & $0.470^{* * *}$ & {$[0.317,0.696]$} & & & 1.168 & {$[0.651,2.097]$} \\
\hline Brong-Ahafo & & & $1.681^{*}$ & {$[1.128,2.506]$} & & & $1.849^{*}$ & {$[1.094,3.126]$} \\
\hline Northern & & & $2.749^{* * *}$ & {$[1.678,4.502]$} & & & $2.498^{*}$ & {$[1.222,5.105]$} \\
\hline Upper East & & & 0.973 & {$[0.633,1.496]$} & & & $7.344^{* * *}$ & {$[3.485,15.48]$} \\
\hline Upper West & & & $9.494^{* * *}$ & {$[3.753,24.02]$} & & & $11.11^{* * *}$ & {$[4.275,28.87]$} \\
\hline \multicolumn{9}{|l|}{ Type of residence } \\
\hline Urban & & & 1 & {$[1,1]$} & & & 1 & {$[1,1]$} \\
\hline Rural & & & 0.911 & {$[0.718,1.156]$} & & & 1.106 & {$[0.763,1.603]$} \\
\hline \multicolumn{9}{|l|}{ Marital status } \\
\hline Never in union & & & 1 & {$[1,1]$} & & & 1 & {$[1,1]$} \\
\hline Currently in union/li & a mans & & $1.373^{* *}$ & {$[1.125,1.676]$} & & & 1.389 & {$[0.938,2.057]$} \\
\hline Formerly in union/li & a man & & 0.971 & {$[0.739,1.276]$} & & & 1.001 & {$[0.565,1.774]$} \\
\hline \multicolumn{9}{|l|}{ Age cohort } \\
\hline $15-19$ & & & 1 & {$[1,1]$} & & & 1 & {$[1,1]$} \\
\hline $20-24$ & & & $0.760^{*}$ & {$[0.608,0.950]$} & & & 0.708 & {$[0.493,1.016]$} \\
\hline $25-29$ & & & 0.968 & {$[0.735,1.274]$} & & & $0.570^{*}$ & {$[0.362,0.898]$} \\
\hline $30-34$ & & & 1.088 & {$[0.815,1.453]$} & & & 0.578 & {$[0.326,1.022]$} \\
\hline $35-39$ & & & 0.990 & {$[0.730,1.342]$} & & & 1.127 & {$[0.623,2.037]$} \\
\hline $40-44$ & & & 0.922 & {$[0.670,1.268]$} & & & 0.774 & {$[0.434,1.379]$} \\
\hline $45-49$ & & & 1.341 & {$[0.941,1.913]$} & & & 1.141 & {$[0.593,2.196]$} \\
\hline $50-54$ & & & - & - & & & 1.033 & {$[0.547,1.950]$} \\
\hline
\end{tabular}


Table 3 Logistic regression results on perceptions of healthcare quality under NHIS and ownership of health insurance (Continued)

\begin{tabular}{|c|c|c|c|c|c|c|c|c|}
\hline $55-59$ & & & - & - & & & 0.873 & {$[0.424,1.801]$} \\
\hline \multicolumn{9}{|l|}{ Religion } \\
\hline Orthodox Christian & & & 1 & {$[1,1]$} & & & 1 & {$[1,1]$} \\
\hline Pentecostal & & & 0.888 & {$[0.751,1.051]$} & & & 1.240 & {$[0.921,1.669]$} \\
\hline Other Christian & & & 1.007 & {$[0.787,1.288]$} & & & $0.634^{* *}$ & {$[0.468,0.860]$} \\
\hline Moslem & & & 0.920 & {$[0.706,1.200]$} & & & 0.952 & {$[0.638,1.419]$} \\
\hline Traditional/Others & & & 1.055 & {$[0.716,1.554]$} & & & $0.563^{* *}$ & {$[0.399,0.794]$} \\
\hline \multicolumn{9}{|l|}{ Ethnicity } \\
\hline Akan & & & 1 & {$[1,1]$} & & & 1 & {$[1,1]$} \\
\hline Ga/Dangme & & & 1.212 & {$[0.825,1.781]$} & & & $1.856^{*}$ & {$[1.043,3.302]$} \\
\hline Ewe & & & 1.364 & {$[0.972,1.912]$} & & & 0.893 & {$[0.533,1.498]$} \\
\hline Mole-Dagbani & & & 1.207 & {$[0.900,1.619]$} & & & 1.465 & {$[0.912,2.354]$} \\
\hline Gurma & & & 1.589 & {$[0.996,2.535]$} & & & $0.581^{*}$ & {$[0.339,0.997]$} \\
\hline Others & & & $1.332^{*}$ & {$[1.001,1.773]$} & & & 0.855 & {$[0.513,1.425]$} \\
\hline \multicolumn{9}{|l|}{ Occupation } \\
\hline Not working & & & 1 & {$[1,1]$} & & & 1 & {$[1,1]$} \\
\hline Professional/Managerial & & & 1.124 & {$[0.800,1.577]$} & & & 0.813 & {$[0.459,1.442]$} \\
\hline Sales/Services & & & 0.996 & {$[0.826,1.201]$} & & & $0.477^{* *}$ & {$[0.291,0.783]$} \\
\hline Agricultural worker & & & 0.788 & {$[0.619,1.004]$} & & & $0.429^{* * *}$ & {$[0.272,0.676]$} \\
\hline Skilled/Unskilled & & & 0.858 & {$[0.673,1.095]$} & & & $0.452^{* * *}$ & {$[0.289,0.706]$} \\
\hline \multicolumn{9}{|l|}{ Currently pregnant } \\
\hline \multicolumn{9}{|l|}{ No/unsure } \\
\hline Yes & & & $2.593^{* * *}$ & {$[1.942,3.462]$} & & & & \\
\hline _Cons & $5.905^{* * *}$ & {$[5.001,6.973]$} & $2.717^{* * *}$ & {$[1.667,4.429]$} & $4.928^{* * *}$ & {$[3.867,6.280]$} & 1.604 & {$[0.727,3.539]$} \\
\hline$A / C$ & 7410.6 & & 6940.2 & & 2713.8 & & 2473.3 & \\
\hline$N$ & 7552 & & 7551 & & 2774 & & 2774 & \\
\hline
\end{tabular}

the low coverage of females in the scheme. Once again, these findings highlight the distortions and inconsistencies in equity for a pro-poor policy such as the NHIS in Ghana. Indeed, removing costs which leads to inequities in access to healthcare is one of the cardinal objectives of the intervention. Consequently, more needs to be done to propel enrolment in high poverty index regions.

The findings also revealed regional-level heterogeneity in perception of quality of health services provided under the insurance. Quality of health services coverage in the country is characterised by significant inequities in favour of the southern portion of the country [35]. Despite this, respondents, women and men in the three northern regions (Northern, Upper East and West) generally had better perceptions of the quality of healthcare with NHIS than those in the other regions. Apparently, this may be due to differential access and experiences with higher standards of care, largely in the private sector compared to the public [36], which are less likely to be cited in any of the three northern regions than the other parts of the country [37]. Thus, those at areas with relatively larger pool of options may demand higher quality of services as compared to regions with limited alternatives.

Our findings show that among women, formal education offered better prospects for owning a health insurance but not really the case for males. Unlike a previous study [23] in Ghana where female education was less effective in predicting health insurance subscription, in this paper, the association observed widens significantly with increasing education. The effect of wealth in this study on women's health insurance subscription was minimal. Thus, education appears more empowering to women than wealth. Kumi-Kyereme and Amo-Adjei (23) made similar observations regarding the minimal role of wealth in women's health insurance subscription. On the other hand, among men, it is rather wealth, which substantially increased the odds of insurance ownership rather than education. Thus, we notice varying associations of education and wealth on health insurance subscription among men and women. 
We also note that perception of quality declined with increased in wealth. In areas where there is high proliferation of private insurance options, the rich are inclined to subscribe to private than national insurance programmes [38] but that is not the case in Ghana. The more plausible reason that could be accounting for the wealth gradient in perception of quality is that they may have higher expectations of quality services that is underpinned by ability to pay, likelihood of being urban areas, better educated and exposure to varied standards of healthcare. Possibly too, with the scheme mainly funded through $2.5 \%$ VAT, the rich may expect/demand more quality attributes since they contribute more to financing the scheme through taxes.

Despite the important findings made in this study, the limitations imposed by the data need to mentioning. First, by relying on a cross sectional data, it is impossible to account for unobserved heterogeneity. The key explanatory variable (perception of quality of health care using NHIS as payment method) for this paper was also measured as perception, which makes it subject. These perceptions maybe fueled by third-party narratives about previous services received and that calls for caution in interpreting the findings.

\section{Conclusion}

This study has demonstrated some significant associations between perceptions of quality of health services to subscribers and health insurance subscription, especially among women. For such a social and pro-poor intervention, it is imperative for the management of the scheme to devote attention to the whole quality mix of services offered to subscribers, whether real or perceived given that whichever way (good or bad) subscribers look at the services rendered when paying for services with the NHIS can have either drive down or up member subscription.

\section{Abbreviations}

DMHIS, District Mutual Health Insurance Scheme; GDHS, Ghana Demographic and Health Survey; NHIS, National Health Insurance Scheme; SSNIT, Social Security and National Insurance Trust.

\section{Acknowledgements}

Authors are grateful to Measure DHS for making the dataset freely available for our use.

Funding

No specific funding was provided for this study.

\section{Availability of data and materials}

The dataset is freely available for public use on www.measuredhs.com. Questionnaires used for the survey are appended to the final report published, which can be found at: http://dhsprogram.com/publications/publication-FR307DHS-Final-Reports.cfm

\section{Authors' contributions}

JAA designed and conceptualized the study. PA, HFA \& MOE coordinated and provided input into the conceptualization. PA, HFA \& MOE reviewed the relevant literature. JAA performed the analysis and interpreted the data. All authors critically reviewed the paper for important intellectual content.

\section{Competing interests}

The authors declare that they have no competing interest.

Consent for publication

Not applicable

\section{Ethical approval and consent to participate}

Ethical approval for the data collection was provided by the Ethical Review Committee of Ghana Health Service, Accra, Ghana and the Institutional Review Board of ICF International, USA.

Each respondent provided informed verbal and written consent to participate in the study. For respondent below 18 years (the statutory age for defining adulthood), parental or legal guardian consent followed by respondent assent was secured.

\section{Author details}

${ }^{1}$ African Population and Health Research Centre, Nairobi, Kenya. ${ }^{2}$ Department of Population and Health, University of Cape Coast, Cape Coast, Ghana.

${ }^{3}$ Department of Business Administration, Valley View University, Oyibi, Ghana.

${ }^{4}$ Department of Accounting and Finance, University of Cape Coast, Cape Coast, Ghana.

Received: 2 May 2016 Accepted: 28 July 2016

Published online: 29 July 2016

\section{References}

1. Atun R. Health systems, systems thinking and innovation. Health Policy Plann. 2012;27 suppl 4:iv4-8.

2. Gottret PE, Schieber $G$. Health financing revisited: a practitioner's guide. Washington DC: World Bank Publications; 2006

3. Vialle-Valentin CE, Serumaga B, Wagner AK, Ross-Degnan D. Evidence on access to medicines for chronic diseases from household surveys in five low-and middle-income countries. Health policy and planning. 2015;30(8): 1044-1052.

4. Xu K, Evans DB, Carrin G, Aguilar-Rivera AM, Musgrove P, Evans T. Protecting households from catastrophic health spending. Health Aff. 2007;26(4):972-83.

5. World Health Organisation. The World Health Report [2010]: Health Systems Financing; the Path to Universal Coverage. Geneva: BWHO; 2010.

6. Sommers BD, Buchmueller T, Decker SL, Carey C, Kronick R. The Affordable Care Act has led to significant gains in health insurance and access to care for young adults. Health Aff. 2013;32(1):165-74.

7. De Allegri M, Sanon M, Sauerborn R. "To enrol or not to enrol?": a qualitative investigation of demand for health insurance in rural West Africa. Soc Sci Med. 2006:62(6):1520-7.

8. Acharya A, Vellakkal S, Taylor F, Masset E, Satija A, Burke M, et al. The impact of health insurance schemes for the informal sector in low-and middle-income countries: a systematic review. World Bank Res Obs. 2013;28(2):236-66

9. Adebayo EF, Uthman OA, Wiysonge CS, Stern EA, Lamont KT, Ataguba JE. A systematic review of factors that affect uptake of community-based health insurance in low-income and middle-income countries. BMC Health Serv Res. 2015;15(1):1.

10. Mulupi S, Kirigia D, Chuma J. Community perceptions of health insurance and their preferred design features: implications for the design of universal health coverage reforms in Kenya. BMC Health Serv Res. 2013;13(1):474.

11. Savadogo G, Souarès A, Sié A, Parmar D, Bibeau G, Sauerborn R. Using a community-based definition of poverty for targeting poor households for premium subsidies in the context of a community health insurance in Burkina Faso. BMC Public Health. 2015;15(1):1.

12. Obse A, Hailemariam D, Normand C. Knowledge of and preferences for health insurance among formal sector employees in Addis Ababa: a qualitative study. BMC Health Serv Res. 2015;15(1):1.

13. National Development Planning Commission. The implementation of the Ghana shared growth and development agenda (GSGDA), 2010-2013. Accra: National Development Planning Commission; 2012.

14. Ghana Statistical Service. Ghana Multiple Indicator Cluster Survey with an Enhanced Malaria Module and Biomarker, 2011, Final Report. Accra, Ghana: Ghana Statistical Service; 2011. 
15. Ghana Statistical Service (GSS), Ghana Health Service (GHS), ICF International. Ghana Demographic and Health Survey 2014. Rockville, Maryland, USA: GSS, GHS, and ICF International; 2015.

16. Dixon J, Tenkorang EY, Luginaah I. Ghana's National Health Insurance Scheme: a national level investigation of members' perceptions of service provision. BMC Int Health Human Rights. 2013;13(1):1.

17. Jehu-Appiah C, Aryeetey G, Spaan E, De Hoop T, Agyepong I, Baltussen R. Equity aspects of the National Health Insurance Scheme in Ghana: Who is enrolling, who is not and why? Soc Sci Med. 2011;72(2):157-65.

18. Daniel KA. The solidarity of self-interest. Social and cultural feasibility of rural health insurance in Ghana. 2003

19. Derbile EK, van der Geest S. Repackaging exemptions under National Health Insurance in Ghana: how can access to care for the poor be improved? Health Policy Plann. 2013;28(6):586-95.

20. Atim C, Sock M. An external evaluation of the Nkoranza community financing health insurance scheme. Ghana: Partnerships for Health Reform, Abt Associates; 2000.

21. National Health Insurance Authority. Annual report 2010. Accra: National Health Insurance Authority; 2011.

22. Sarpong N, Loag W, Fobil J, Meyer CG, Adu-Sarkodie Y, May J, et al. National health insurance coverage and socio-economic status in a rural district of Ghana. Tropical Med Int Health. 2010;15(2):191-7.

23. Kumi-Kyereme A, Amo-Adjei J. Effects of spatial location and household wealth on health insurance subscription among women in Ghana. BMC Health Serv Res. 2013;13(1):1.

24. Criel B, Waelkens MP. Declining subscriptions to the Maliando Mutual Health Organisation in Guinea-Conakry (West Africa): what is going wrong? Soc Sci Med. 2003:57(7):1205-19. doi:10.1016/S0277-9536(02)00495-1.

25. Basaza R, Criel B, Van der Stuyft P. Community health insurance in Uganda: Why does enrolment remain low? A view from beneath. Health Policy. 2008;87(2):172-84. doi:10.1016/j.healthpol.2007.12.008.

26. Von Bothmer Ml, Fridlund B. Gender differences in health habits and in motivation for a healthy lifestyle among Swedish university students. Nurs Health Sci. 2005;7(2):107-18.

27. Parmar D, De Allegri M, Savadogo G, Sauerborn R. Do community-based health insurance schemes fulfil the promise of equity? A study from Burkina Faso. Health Policy Plann. 2014;29(1):76-84.

28. Martin $B C$, McMillan JA. The impact of implementing a more restrictive prescription limit on Medicaid recipients: effects on cost, therapy, and outof-pocket expenditures. Med Care. 1996;34(7):686-701.

29. Jehu-Appiah C, Aryeetey G, Agyepong I, Spaan E, Baltussen R. Household perceptions and their implications for enrolment in the National Health Insurance Scheme in Ghana. Health Policy Plann. 2012;27(3):222-33.

30. Darley WK, Smith RE. Gender differences in information processing strategies: An empirical test of the selectivity model in advertising response. J Advert. 1995:24(1):41-56

31. Atinga RA, Abiiro GA, Kuganab-Lem RB. Factors influencing the decision to drop out of health insurance enrolment among urban slum dwellers in Ghana. Tropical Med Int Health. 2015;20(3):312-21. doi:10.1111/tmi.12433.

32. Brabin $L$, Brabin $B J$, Gies $S$. Influence of iron status on risk of maternal or neonatal infection and on neonatal mortality with an emphasis on developing countries. Nutr Rev. 2013;71(8):528-40.

33. Dixon J, Tenkorang EY, Luginaah IN, Kuuire VZ, Boateng GO. National health insurance scheme enrolment and antenatal care among women in Ghana: is there any relationship? Tropical Med Int Health. 2014;19(1):98-106. doi:10. $1111 /$ tmi.12223.

34. Ghana Statistical Service. Ghana Living Standards Survey Round 6 (GLSS 6): Poverty Profile in Ghana (2005-2013). Accra: Ghana Statistical Service; 2014.

35. Owusu G. An assessment of Regional and Gender equity in healthcare coverage under different healthcare policies in Ghana. Ghana J Geogr. 2014; 6(1):42-62.

36. Agyepong IA, Anafi P, Asiamah E, Ansah EK, Ashon DA, Narh-Dometey C. Health worker (internal customer) satisfaction and motivation in the public sector in Ghana. Int J Health Plann Manag. 2004;19(4):319-36.

37. Bitran RA. Private health sector assessment in Ghana. Washington DC: World Bank Publications; 2011

38. Van Doorslaer E, Masseria C, Koolman X, Group OHER. Inequalities in access to medical care by income in developed countries. Can Med Assoc J. 2006;174(2):177-83.

\section{Submit your next manuscript to BioMed Central and we will help you at every step:}

- We accept pre-submission inquiries

- Our selector tool helps you to find the most relevant journal

- We provide round the clock customer support

- Convenient online submission

- Thorough peer review

- Inclusion in PubMed and all major indexing services

- Maximum visibility for your research

Submit your manuscript at www.biomedcentral.com/submit
Biomed Central 